\title{
Risk and Return
}

\section{David G McMillan*}

University of Stirling, UK

The aim of this editorial is to open discussion again regarding the risk-return relationship in stock market data. While this editorial will not reach any definitive conclusion it is hoped that the results presented here will stimulate future debate and continuing work. The risk return trade-off is a fundamental relationship in finance. It suggests that the expected return is positively related to volatility, often proxied using the conditional variance estimated from a GARCH-M model. However the empirical evidence based, which is typically based on index return series is mixed. A brief glance at the literature reveals that a positive relationship between return and risk (conditional variance) has been reported by French et al. [1], Chou [2], Campbell and Hentschel [3], Lundblad [4] and Müller et al. [5]. However, a negative relationship is reported by Nelson [6], Glosten et al. [7] and Jensen and Lunde [8] among others.

Explanations for the lack of a consensus in the empirical results include small sample sizes [4], the use of different sampling frequencies [9] and non-linearities [10]. Furthermore, Yang [11] argues that the volatility feedback effect proposed by French et al. [1] should be accounted for when examining the risk return trade-off in the GARCH-M framework as volatility feedback can induce a negative relationship. Furthermore, of course, the existence of a positive relationship arises from our belief in risk aversion, where an investor will only take on more risk if there is an accompanying increase in (expected) return. A negative relationship could arise where investors exhibit risk-seeking behaviour. While we generally rule out such behaviour, it may be that investors exhibit behavioural biases in the form of prospect theory, which could also drive a negative relationship (Table 1).

A final point to consider is whether the conditional variance is the appropriate measure for risk. We think of risk in terms of losses and yet the conditional variance includes both sides of the distribution. A measure that only includes the downside is the semi-variance, essentially the variance calculated for value below a particular threshold, typically zero. This measure will differ from the variance over the whole distribution particularly with a skewed distribution as is often found in finance.

The above table presents the estimated coefficient that determines the relationship between return and risk, where risk is proxied by the GARCH model or by the semi-variance. Evident from this table is that the GARCH estimate produce insignificant values that vary widely, including negative values. In contrast, the semi-variance values are all positive and statistically significant. Furthermore, they are all of a similar magnitude, which is perhaps to be expected of similar markets.
Estimates and p-values of risk-return coefficient estimated for the $\mathrm{G} 7$ markets using a GARCH $(1,1)-\mathrm{M}$ model and regression of returns on the semi-variance.

\begin{tabular}{|l|l|l|}
\hline Canada & GARCH(1,1)-M & Semi-variance \\
\hline France & $-0.049(0.99)$ & $1.334(0.00)$ \\
\hline Germany & $3.467(0.18)$ & $1.398(0.00)$ \\
\hline Italy & $0.158(0.92)$ & $1.321(0.00)$ \\
\hline Japan & $-0.787(0.72)$ & $1.464(0.00)$ \\
\hline UK & $-1.486(0.41)$ & $1.351(0.00)$ \\
\hline US & $2.519(0.23)$ & $1.341(0.00)$ \\
\hline
\end{tabular}

Table 1: Estimates and p-values of risk-return coefficient estimated for the G7 markets using a GARCH $(1,1)-\mathrm{M}$ model and regression of returns on the semi-variance.

As noted above, risk and return remains one of the most important issues in finance and the perceived difference in reported results, including negative and insignificant values requires further research and explanation, including the use of different proxies for risk.

\section{References}

1. French KR, Schwert GW, Stambaugh RF (1987) Expected stock returns and Volatility. Journal of Financial Economics 19: 3-29.

2. Chou R (1988) Volatility persistence and stock evaluations: some empirical evidence using GARCH. Journal of Applied Econometrics 3: 279-294.

3. Campbell JY, Hentschel $L$ (1992) No news is good news: an asymmetric model ofchanging volatility in stock returns. Journal of Financial Economics 31: 281318.

4. Lundblad C (2007) The risk return tradeoff in the long run: 1836-2003. Journal of Financial Economics 85: 123-150.

5. Müller G, Durand RB, Maller RA (2011) The risk-return tradeoff: A COGARCH analysis of Merton's hypothesis. Journal of Empirical Finance 18: 306-320.

6. Nelson DB (1991) Conditional Heteroskedasticity in Asset Returns: A New Approach. Econometrica 59: 347-370.

7. Glosten LR, Jagannathan R, Runkle DE (1993) On the relation between the expected value and the volatility of the nominal excess return on stocks. Journal of Finance 48: 1779-1801.

8. Jensen MB, Lunde A (2001) The NIG-S \& ARCH model: a fat-tailed, stochastic and autoregressive conditional heteroskedastic volatility model. Econometrics Journal 4: 319-342.

9. Ghysels E, Santa-Clara P, Valkanov R (2005) There is a risk return trade-off after all. Journal of Financial Economics 76: 509-548.

10. Rossi A, Timmermann A (2010) What is the shape of the risk return relation? Working Paper.

11. Yang M (2010) Volatility Feedback and Risk Premium in GARCH Models with Generalized Hyperbolic Distributions. Studies in Nonlinear Dynamics \& Econometrics 15: 124-142.

*Corresponding author: David G McMillan, Professor, University of Stirling, UK E-mail: david.mcmillan@stir.ac.uk

Received January 17, 2013; Accepted January 18, 2013; Published January 19 2013

Citation: McMillan DG (2013) Risk and Return. J Bus \& Fin Aff 2:e130. doi:10.4172/2167-0234.1000e130

Copyright: (C) 2013 McMillan DG. This is an open-access article distributed unde the terms of the Creative Commons Attribution License, which permits unrestricted use, distribution, and reproduction in any medium, provided the original author and source are credited. 